\title{
Human Papillomavirus-Related Multiphenotypic Sinonasal Carcinoma-An Even Broader Tumor Entity?
}

\author{
Mark Zupancic and Anders Näsman * (D) \\ Department of Oncology-Pathology, Karolinska Institutet, Bioclinicum J6:20, Karolinska University Hospital, \\ 17164 Stockholm, Sweden; Mark.Zupancic@ki.se \\ * Correspondence: Anders.Nasman@ki.se
}

check for

updates

Citation: Zupancic, M.; Näsman, A. Human Papillomavirus-Related Multiphenotypic Sinonasal Carcinoma-An Even Broader Tumor Entity? Viruses 2021, 13, 1861. https://doi.org/10.3390/v13091861

Academic Editor: Zhi-Ming Zheng

Received: 11 August 2021

Accepted: 13 September 2021

Published: 17 September 2021

Publisher's Note: MDPI stays neutral with regard to jurisdictional claims in published maps and institutional affiliations.

Copyright: (c) 2021 by the authors. Licensee MDPI, Basel, Switzerland. This article is an open access article distributed under the terms and conditions of the Creative Commons Attribution (CC BY) license (https:/ / creativecommons.org/licenses/by/ $4.0 /)$.

\begin{abstract}
Human papillomavirus (HPV)-related multiphenotypic sinonasal carcinoma (HMSC) is a recently defined tumor subtype with apparent favorable clinical outcome despite aggressive histomorphology. However, in recent years, additional numbers of cases, with more variable features and at locations outside the sinonasal region, have complicated the definition of HMSC. Here, we have performed a systematic review of all cases described so far in order to accumulate more knowledge. We identified 127 articles published between 2013 and 2021, of which 21 presented unique cases. In total, 79 unique patient cases were identified and their clinical and micromorphological nature are herein summarized. In our opinion, better clinical follow-up data and a more detailed tumor characterization are preferably needed before HMSC can finally be justified as its own tumor entity.
\end{abstract}

Keywords: human papillomavirus; human papillomavirus-related multiphenotypic sinonasal carcinoma; head and neck cancer; basaloid squamous cell carcinoma

\section{Introduction}

Since the first case report in 2013 by Bishop and colleagues, in which six patients with the potentially new entity at that time called human papillomavirus (HPV)-related carcinoma with adenoid cystic carcinoma-like features was described [1], additional reports have been published from various parts of the world. Although there have been a few early attempts to summarize all of the published cases of HPV-related multiphenotypic sinonasal carcinoma (HMSC), no systematic review has, to our knowledge, been conducted so far [2]. In addition, HMSC was initially described as a relatively uniform tumor type in terms of localization, clinical behavior, HPV subtype and histomorphology. However, recent case reports have suggested that the clinical and micromorphological spectrum might be broader than initially reported. Therefore, we aimed to review the current knowledge about HMSC by performing a systematic review of, to our knowledge, all cases published so far and summarize their clinical and histopathological characteristics.

\section{Materials and Methods}

We adhered to the PRISMA guidelines and searched PubMed, using the search terms " "multiphenotypic" OR "multiphenotypic sinonasal" OR "adenoid cystic like"'" in May 2021 and found 127 unique articles, of which 69 articles were published after the first case report in $2013(n=70)$. Subsequently, one researcher $(A N)$ reviewed the abstracts of all 70 articles and found 21 articles that met the inclusion criteria (a patient case or a series of patients diagnosed with "HPV-related carcinoma with adenoid cystic carcinoma-like features" /HMSC, written in English) (Figure 1). Full-text versions of all manuscripts were available in all cases. Three articles had overlapping patient cases [1,3,4], with all patients covered in Bishop et al. 2017 [3]. 


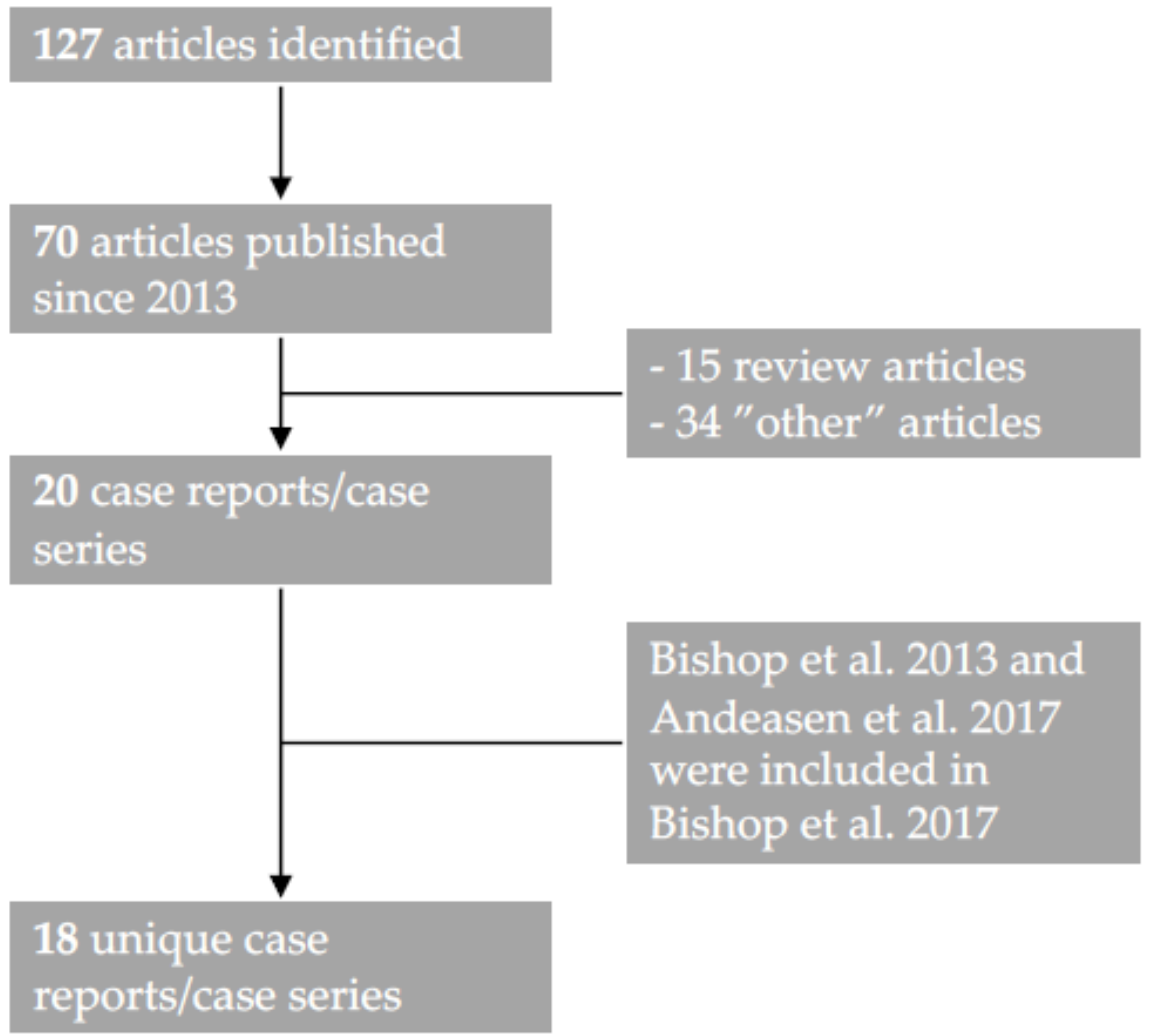

Figure 1. Flow diagram with the selection process of articles. Initially, 127 articles were identified using the search terms "“multiphenotypic" OR "multiphenotypic sinonasal" OR "adenoid cystic like"'", of which 70 manuscripts were published since the first case report in 2013. After reviewing all abstracts, 20 reports were identified, excluding 15 review articles without additional cases reported and 34 articles outside the topic ("other" articles). Bishop et al. 2017 [3] summarized and included all data from Bishop et al. 2013 [1] and Andreasen 2017 [4] and added 35 new unique cases. Therefore, 18 unique case series were identified.

Patient and tumor data (age, sex, tumor localization and size, treatment, outcome and follow-up time in months after treatment), pathological parameters (morphology, immunohistochemistry staining (IHC) data) and HPV status (p16, HPV DNA PCR, HPV DNA ISH and HPV RNA ISH status) were collected by two researchers independently (AN, MZ). The outcomes were classified as "No evidence of disease" (NED), "Local relapse" (LR), "Distant metastasis" (DM) or "Dead of disease" (DOD) and patients were classified according to their first reported event. Event-free survival was calculated and was defined as the time from first diagnosis (months) until the first reported event (LR, DM, DOD). Patients with NED were censored at the last day of follow-up. All statistics were performed in SPSS (IBM Corp. Released 2017. IBM SPSS Statistics for Macintosh, Version 25.0. Armonk, NY, USA: IBM Corp.).

\section{Results}

\subsection{Patients and Clinical Characteristics}

In total, 21 articles were identified, including 79 unique patients diagnosed with HMSC (Table 1), and of these patients, 39 (51\%) were women, $38(49 \%)$ men and 1 case was not specified. Seventy-eight patients had a primary tumor within the head and neck region, while one case was reported outside this region (breast). The mean and median ages were 53.7 and 53 years, respectively, for the total cohort (53.6 and 53 years, respectively, in patients with head and neck tumors). 


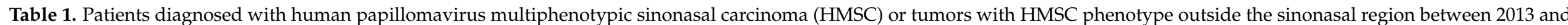
2021 and their clinical and tumor characteristics.

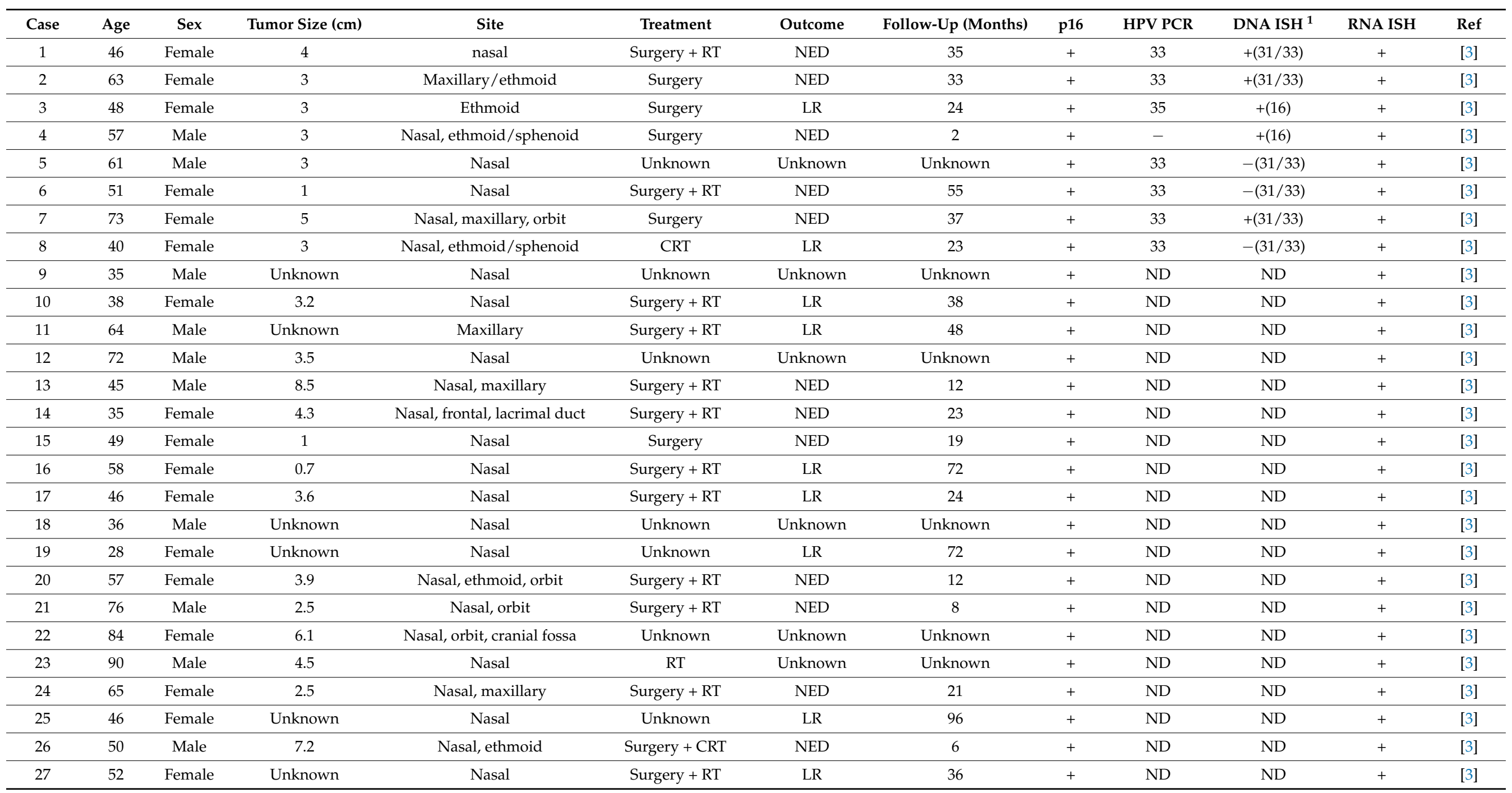


Table 1. Cont

\begin{tabular}{|c|c|c|c|c|c|c|c|c|c|c|c|c|}
\hline Case & Age & Sex & Tumor Size (cm) & Site & Treatment & Outcome & Follow-Up (Months) & p16 & HPV PCR & DNA ISH $^{1}$ & RNA ISH & Ref \\
\hline 28 & 60 & Female & 3.9 & Nasal & Surgery + RT & LR & 130 & + & 56 & + & + & [3] \\
\hline 29 & 53 & Female & 3 & Nasal & Surgery & NED & 56 & + & 33 & $+(33)$ & + & [3] \\
\hline 30 & 48 & Female & 4 & Nasal & Surgery & NED & 39 & + & 33 & $+(33)$ & + & [3] \\
\hline 31 & 51 & Female & 2 & Nasal, ethmoid/sphenoid & Surgery + RT & NED & 27 & + & 35 & + & + & [3] \\
\hline 32 & 29 & Male & 5 & Nasal & Surgery & LR & 23 & + & 35 & + & + & [3] \\
\hline 33 & 53 & Male & 3 & Nasal & Surgery & NED & 15 & + & 33 & + & + & [3] \\
\hline 34 & 61 & Male & 7 & Nasal & Surgery & NED & 3 & + & ND & ND & + & [3] \\
\hline 35 & 53 & Male & Unknown & Nasal, frontal & Surgery & LR & 36 & + & ND & ND & + & [3] \\
\hline 36 & 51 & Male & 3.6 & Nasal & Surgery + RT & LR & 42 & + & ND & ND & + & [3] \\
\hline 37 & 53 & Male & 5 & Nasal & Surgery & NED & 3 & + & ND & ND & + & [3] \\
\hline 38 & 63 & Female & 6 & Nasal, maxillary & Unknown & Unknown & Unknown & + & ND & ND & + & [3] \\
\hline 39 & 66 & Male & 3.7 & Maxillary & Surgery & NED & 3 & + & ND & ND & + & [3] \\
\hline 40 & 50 & Male & 6.5 & Nasal, maxillary/ethmoid & Surgery & NED & 6 & + & ND & ND & + & [3] \\
\hline 41 & 53 & Female & 3.8 & Nasal & Surgery & NED & 1 & + & ND & ND & + & [3] \\
\hline 43 & 37 & Female & 3.5 & Nasal, maxillary & Surgery + CRT & NED & 42 & + & ND & ND & + & [3] \\
\hline 44 & 51 & Female & Unknown & Nasal & Unknown & Unknown & Unknown & + & ND & ND & + & [3] \\
\hline 45 & 48 & Male & 2.2 & Nasal & Surgery & NED & 22 & + & ND & ND & + & [3] \\
\hline 46 & 58 & Male & 3,4 & Nasal & Surgery & NED & 3 & + & ND & ND & + & [3] \\
\hline 47 & 46 & Male & 1.3 & Nasal & Surgery & NED & 8 & + & ND & ND & + & [3] \\
\hline 48 & 46 & Male & Unknown & Nasal & Unknown & Unknown & Unknown & + & ND & ND & + & [3] \\
\hline 49 & 60 & Female & 4.2 & Nasal, maxillary & Surgery + CRT & NED & 10 & + & ND & ND & + & [3] \\
\hline 50 & 75 & Female & 2.5 & Nasal & Surgery & NED & 12 & + & ND & + & ND & [5] \\
\hline 51 & 37 & Male & 3 & Nasal & Surgery & Unknown & Unknown & + & $*$ & + & ND & [6] \\
\hline 52 & 30 & Male & 0.9 & Middle turbinate & Surgery & NED & 184 & + & $*$ & + & ND & [6] \\
\hline 53 & 48 & Male & 2.2 & Posterior nasal cavity & Surgery & NED & 20 & + & $*$ & + & ND & [6] \\
\hline 54 & 46 & Male & 1.3 & Middle turbinate & Surgery & NED & 5 & + & $*$ & + & ND & [6] \\
\hline 55 & 58 & Male & 3.4 & Middle turbinate & Surgery + RT & NED & 3 & + & * & + & ND & [6] \\
\hline
\end{tabular}


Table 1. Cont

\begin{tabular}{|c|c|c|c|c|c|c|c|c|c|c|c|c|}
\hline Case & Age & Sex & Tumor Size (cm) & Site & Treatment & Outcome & Follow-Up (Months) & p16 & HPV PCR & DNA ISH $^{1}$ & RNA ISH & Ref \\
\hline 56 & 60 & Male & 3.5 & Nasal, ethmoid & Surgery & Unknown & Unknown & + & 35 & ND & ND & [7] \\
\hline 57 & 46 & Unknown & Unknown & Inferior turbinate & Surgery & Unknown & Unknown & + & 33 & ND & ND & [7] \\
\hline 58 & 69 & Female & Unknown & Nasal & Surgery & LR & 24 & + & ND & $\mathrm{ND}(33)$ & + & [8] \\
\hline 59 & 42 & Female & 3 & Nasal & Surgery & NED & Unknown & + & 56,68 & ND & ND & [9] \\
\hline 60 & 60 & Male & Unknown & Nasal & Surgery + RT & DOD & 11 & + & 14 & ND & ND & [10] \\
\hline 61 & 40 & Male & 1.6 & Nasal & Unknown & Unknown & Unknown & + & ND & - & + & [11] \\
\hline 62 & 60 & Male & 1.5 & Nasal & Unknown & Unknown & Unknown & + & ND & + & + & [11] \\
\hline 63 & 39 & Female & 3.5 & Nasal & Unknown & Unknown & Unknown & + & ND & + & + & [11] \\
\hline 64 & 76 & Male & 1.5 & Nasal & Unknown & Unknown & Unknown & + & ND & + & + & [11] \\
\hline 65 & 36 & Female & 1 & Nasal & Unknown & Unknown & Unknown & + & ND & + & + & [11] \\
\hline 66 & 32 & Female & 2.4 & Nasal & Unknown & Unknown & Unknown & + & ND & + & + & [11] \\
\hline 67 & 48 & Female & 9.5 & Nasal & Surgery & NED & 12 & + & 52 & ND & ND & [12] \\
\hline 68 & 66 & Male & Unknown & Nasal & Surgery & LR & 192 & + & 33,51 & ND & ND & [13] \\
\hline 69 & 54 & Female & Unknown & Nasal & Surgery & NED & 9 & + & 16 & ND & ND & [14] \\
\hline 71 & 65 & Female & Unknown & Middle concha & Surgery & NED & 50 & + & 56 & ND & ND & [16] \\
\hline 72 & 54 & Female & Unknown & Nasal & Surgery & NED & 38 & + & 82 & ND & ND & [16] \\
\hline 73 & 46 & Female & Unknown & Nasal & Surgery & NED & 30 & + & 56 & ND & ND & [16] \\
\hline 74 & 60 & Female & Unknown & Nasal & Surgery + CRT & NED & 3 & + & 33 & ND & ND & [16] \\
\hline 75 & 65 & Male & Unknown & Nasal & Surgery + RT & DM & 23 & + & 16 & ND & ND & [17] \\
\hline 76 & 49 & Male & 2 & Nasal & Surgery & NED & 18 & + & 33 & ND & ND & [18] \\
\hline 77 & 84 & Male & Unknown & Nasal & Surgery + RT & NED & 6 & + & ND & $+(\mathrm{ND})$ & ND & [19] \\
\hline 78 & 54 & Male & 2 & Tonsil & Surgery + RT & NED & 24 & + & ND & ND & $+(16)$ & [20] \\
\hline 79 & 45 & Female & 10 & Breast & Unknown & Unknown & Unknown & ND & ND & ND & + & [21] \\
\hline
\end{tabular}

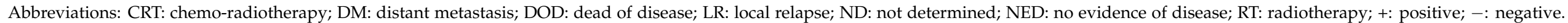

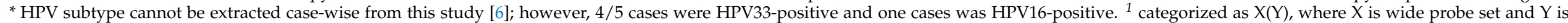

type-specific probe. 
When focusing on patients with head and neck tumors only, the most common primary site was the nasal cavity but, notably, the primary site was not restricted to the sinonasal region. Tumor size was specified in 57 cases and the total mean size was $3.5 \mathrm{~cm}$. The presence of regional metastasis was only reported in one case (case 78; primary tonsil tumor). For cases in which treatment was specified $(n=61)$, the most common treatment modality was surgery only $(n=34)$, followed by surgery and radiotherapy $(\mathrm{RT})(n=21)$; surgery, RT and chemotherapy (CT) $(n=4)$; RT alone $(n=1)$; and CT alone $(n=1)$.

Patients diagnosed with HMSC within the head and neck region had 31.3 and 23 months mean and median follow-up time, respectively (Table 1). The outcome was defined in 59/78 cases (76\%) and of these, 42/59 (71\%) had NED at the end of their follow-up. Fifteen cases $(25 \%)$ had an LR, $1 / 59(2 \%)$ patients died from disease and another patient $(1 / 59 ; 2 \%)$ had a DM. All patients' event-free survival is presented in Figure 2 . The mean and median event-free survival times were 81.7 months (95\% CI: 52.1-111) and 72 months (95\% CI: 41.1-103), respectively.

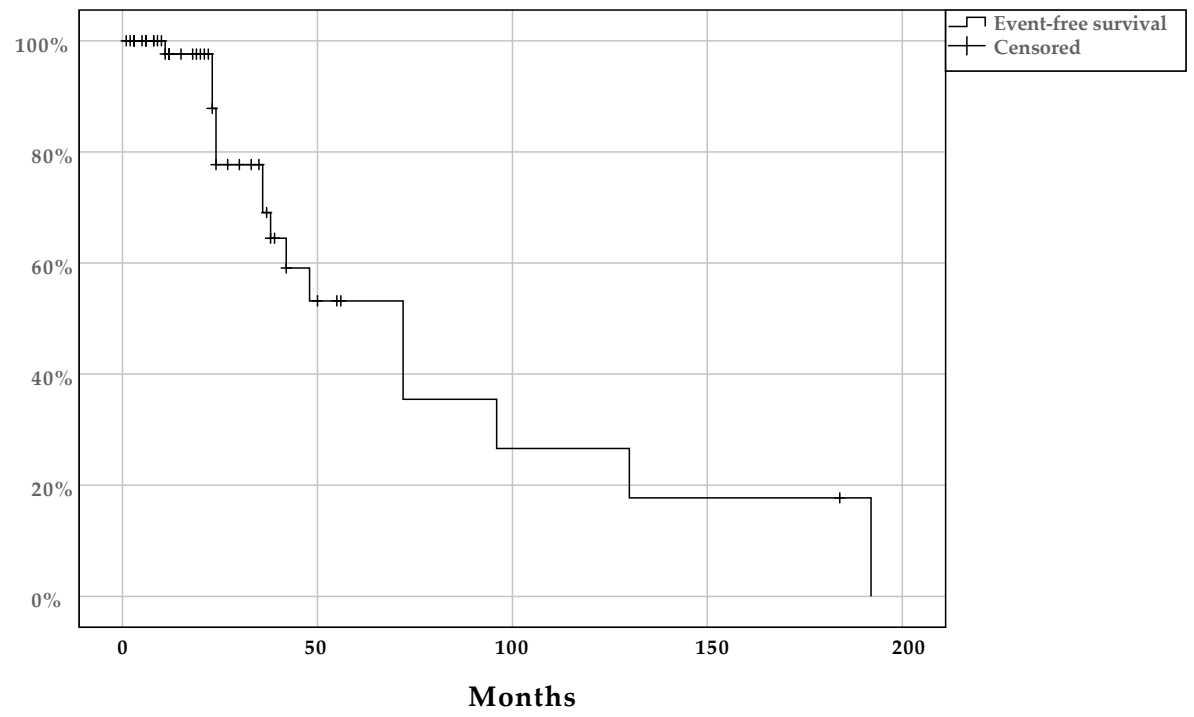

Figure 2. Kaplan-Meier plot with event-free survival in patients diagnosed with multiphenotypic sinonasal carcinoma (HMSC) within the head and neck region (including tonsils).

\subsection{Histomorphology, Immunohistochemistry and HPV Status in HMSC}

Tumors diagnosed as HMSC were often micro-morphologically described as a basaloid proliferation (78/79 cases; not defined in 1 case). The presence of solid areas was described in $76 / 79$ cases ( 1 without solid areas and 2 not defined) and the presence of cribriform areas was observed in 53/79 cases (20 without cribriform areas and 6 not defined). Focal "squamous differentiation" within the tumor was observed in 15/79 cases (57 without squamous differentiation and 7 not defined). An associated dysplastic squamous epithelium was noticed in 50/79 cases (26 without and 3 not defined). Moreover, perineural (Pn) and lymphovascular invasion (LVI) were rarely observed and were detected in only 5 and 1 cases, respectively (Pn: 5/79 cases, 50 without and 24 not defined; LVI: 1/79 cases, 52 without and 26 not defined). A well-defined, at least focal, abluminal myoepithelial IHC staining (e.g., p40, p63, etc.) was, according to the authors of the manuscripts, observed in 53/79 cases (20 without and 6 not defined). At least focal luminal IHC staining (e.g., CD117) was identified in $40 / 70$ cases (19 without and 20 not described).

Various methods were used to define HPV status and the most common method was the presence of p16 overexpression as a surrogate marker of the presence of HPV, used in $78 / 79$ case (78/78 cases within the head and neck region) (Table 1 ). HPV subtype was only assessed in a minority of cases, by PCR $(n=31)$. Here, HPV 33 dominated, with 17 cases followed by 4 cases with HPV35, 4 cases of HPV56 and 3 cases of HPV16 (Table 1); all types found were within species 9 of the alpha-papillomavirus genus [22]. 


\section{Discussion}

This is, to our knowledge, the first systematic review of HMSC in which all patients diagnosed with HMSC since the first report in 2013 were included and wherein we have attempted to summarize all available clinical and morphological data published so far. Taken together, the overall picture of the nature of the potentially new tumor entity HMSC has slightly changed since the initial summary reports $[2,12,19,23]$, but is still mainly characterized by its indolent course despite an aggressive histomorphology.

Patients diagnosed with HMSC were clinically characterized by being young at diagnosis (53.7 years), without any sex predisposition and with a favorable prognosis after treatment, which most often consisted of surgery with/without RT. Interestingly, occurrence of distant metastasis was rare and no regional metastasis was reported and patients had a generally favorable survival rate. However, it is important to note that the follow-up time was lacking or was short in many cases and therefore the prognostic impact of the micromorphological diagnosis must be interpreted with caution.

The most common method to confirm the presence of HPV was to use the overexpression of $\mathrm{p} 16$ as a surrogate marker for HPV. In a minority of cases, the HPV subtype was determined by PCR. In these cases, HPV33 dominated, followed by HPV35, 56, 16, etc. Previous studies have emphasized the dominance of HPV33 as a feature of HMSC [2]. However, as mentioned, the number of cases with a defined HPV subtype was too limited to draw any clear conclusions about subtype dominance and all HPV types detected in HMSC are included in species 9 of the HPV alpha-genus [22]. Moreover, there is, to our knowledge, no evidence of tissue tropism nor morphological correlation for specific HPV types within the same species of HPV. Therefore, it is possible that the HPV type frequency may change as more cases as published and specific HPV types should not be considered a feature of any carcinoma type.

The histomorphology varied slightly between cases. Most cases were characterized by a basaloid proliferation with the presence of solid areas. Many cases also showed a tendency for a biphasic IHC staining. An obvious differential diagnosis to HMSC is adenoid cystic carcinoma (ACC), which could be ruled out in the majority of cases, e.g., by the presence of a dysplastic epithelium, "squamous differentiation", absence of Pn and absence of MYB gene fusions (data not shown).

Another differential diagnosis, however, may be a basaloid squamous cell carcinoma (SCC), which is characterized by a basaloid atypical proliferation that may contain cribriform areas and glad-like spaces [24]. Notably, the classical basaloid SCC occurs mostly in men and is rarely observed in the nasal cavity, although it can be HPV-related; but in contrast to HMSC, it also often presents with nodal metastases [25].

Subsequently, although there seem to be clinical differences between a basaloid SCC and HMSC, their micromorphological distinctions are not always clear-cut. Moreover, this study also highlights that HMSC-like morphology may occur outside the sinonasal region and, therefore, further studies are needed to better discriminate between these tumor variants.

In addition, it is worth noting that no cases that arose within the sinonasal region presented with a regional metastasis; however, all cases disclosed outside that region did. Whether this finding is attributed to factors related to anatomical location or differences in tumor nature despite similar morphology remains to be elucidated.

In summary, HMSC is a new subtype, according to WHO 2017, of non-keratinizing squamous cell carcinoma of the sinonasal region with an indolent clinical course [26]. However, in our opinion, better clinical follow-up data and a more detailed tumor characterization are preferably needed before HMSC can finally be justified and better-defined as its own tumor entity.

Author Contributions: Conceptualization, M.Z. and A.N.; methodology, M.Z. and A.N.; software, M.Z. and A.N.; validation, M.Z. and A.N.; formal analysis, M.Z. and A.N.; investigation, M.Z. and A.N.; resources, A.N.; data curation, M.Z. and A.N.; writing-original draft preparation, M.Z. and A.N.; writing - review and editing, M.Z. and A.N.; visualization, M.Z. and A.N.; supervision, A.N.; 
project administration, A.N.; funding acquisition, A.N. All authors have read and agreed to the published version of the manuscript.

Funding: This research was funded by THE SWEDISH CANCER SOCIETY, grant numbers 200778P, 200764Fk and 210292JCIA; STOCKHOLMS LÄNS LANDSTING (ALF), grant number 20200059; THE CANCER AND ALLERGY FOUNDATION, grant number 10137; MAGNUS BERGVALLS STIFTELSE, grant number 2020-03737; TORNSPIRAN, grant number 2020; THE STOCKHOLM CANCER SOCIETY, grant number 201242; and SVENSKA LÄKARESÄLLSKAPET, grant number SLS-935256.

Institutional Review Board Statement: Not applicable.

Informed Consent Statement: Not applicable.

Data Availability Statement: Not applicable.

Conflicts of Interest: The authors declare no conflict of interest.

\section{References}

1. Bishop, J.A.; Ogawa, T.; Stelow, E.B.; Moskaluk, C.A.; Koch, W.M.; Pai, S.I.; Westra, W.H. Human papillomavirus-related carcinoma with adenoid cystic-like features: A peculiar variant of head and neck cancer restricted to the sinonasal tract. Am. J. Surg. Pathol. 2013, 37, 836-844. [CrossRef]

2. Chen, C.C.; Yang, S.F. Human Papillomavirus-Related Carcinoma With Adenoid Cystic-like Features of the Sinonasal Tract (Also Known as Human Papillomavirus-Related Multiphenotypic Sinonasal Carcinoma). Arch. Pathol. Lab. Med. 2019, 143, 1420-1424. [CrossRef] [PubMed]

3. Bishop, J.A.; Andreasen, S.; Hang, J.F.; Bullock, M.J.; Chen, T.Y.; Franchi, A.; Garcia, J.J.; Gnepp, D.R.; Gomez-Fernandez, C.R.; Ihrler, S.; et al. HPV-related Multiphenotypic Sinonasal Carcinoma: An Expanded Series of 49 Cases of the Tumor Formerly Known as HPV-related Carcinoma With Adenoid Cystic Carcinoma-like Features. Am. J. Surg. Pathol. 2017, 41, 1690-1701. [CrossRef] [PubMed]

4. Andreasen, S.; Bishop, J.A.; Hansen, T.V.; Westra, W.H.; Bilde, A.; von Buchwald, C.; Kiss, K. Human papillomavirus-related carcinoma with adenoid cystic-like features of the sinonasal tract: Clinical and morphological characterization of six new cases. Histopathology 2017, 70, 880-888. [CrossRef] [PubMed]

5. Hwang, S.J.; Ok, S.; Lee, H.M.; Lee, E.; Park, I.H. Human papillomavirus-related carcinoma with adenoid cystic-like features of the inferior turbinate: A case report. Auris Nasus Larynx 2015, 42, 53-55. [CrossRef] [PubMed]

6. Hang, J.F.; Hsieh, M.S.; Li, W.Y.; Chen, J.Y.; Lin, S.Y.; Liu, S.H.; Pan, C.C.; Kuo, Y.J. Human papillomavirus-related carcinoma with adenoid cystic-like features: A series of five cases expanding the pathological spectrum. Histopathology 2017, 71, 887-896. [CrossRef]

7. Chouake, R.J.; Cohen, M.; Iloreta, A.M. Case report: HPV-related carcinoma with adenoid cystic-like features of the sinonasal tract. Laryngoscope 2018, 128, 1515-1517. [CrossRef]

8. Shah, A.A.; Lamarre, E.D.; Bishop, J.A. Human Papillomavirus-Related Multiphenotypic Sinonasal Carcinoma: A Case Report Documenting the Potential for Very Late Tumor Recurrence. Head Neck Pathol. 2018, 12, 623-628. [CrossRef]

9. Saenz Gonzalez, A.F.; Morera Serna, E.; Quintero Duarte, A.M.; Ramos Asensio, R. Recurrence of human papillomavirus-related carcinoma with adenoid cystic-like features. Acta Otorrinolaringol. Esp. 2019, 70, 119-121. [CrossRef]

10. Hung, Y.; Chung, Y.Y.; Chen, M.L.; Guo, J.Y. HPV-related sinonasal carcinoma with adenoid cystic-like features with intracranial invasion. Ear Nose Throat J. 2018, 97, 191-192.

11. Hsieh, M.S.; Lee, Y.H.; Jin, Y.T.; Huang, W.C. Strong SOX10 expression in human papillomavirus-related multiphenotypic sinonasal carcinoma: Report of 6 new cases validated by high-risk human papillomavirus mRNA in situ hybridization test. Hum. Pathol. 2018, 82, 264-272. [CrossRef]

12. Adamane, S.A.; Mittal, N.; Teni, T.; Pawar, S.; Waghole, R.; Bal, M. Human Papillomavirus-Related Multiphenotypic Sinonasal Carcinoma with Unique HPV type 52 Association: A Case Report with Review of Literature. Head Neck Pathol. 2019, 13, 331-338. [CrossRef]

13. Ahn, B.; Kim, E.; Oh, H.; Chae, Y.S.; Kim, C.H.; Lee, Y.; Lee, J.H.; Lee, Y.J. Human Papillomavirus-Related Multiphenotypic Sinonasal Carcinoma with Late Recurrence. J. Pathol. Transl. Med. 2019, 53, 337-340. [CrossRef]

14. Ching, D.; Pirasteh, S.; Ly, C. HPV-Related Multiphenotypic Sinonasal Carcinoma: A Unique Case. Int. J. Surg. Pathol. 2019, 27, 888-892. [CrossRef]

15. Brzezinska, K.; Hammad, A. Human Papillomavirus-Related Multiphenotypic Sinonasal Carcinoma: A Recent Discovery. A Case Report and Literature Review. Head Neck Pathol. 2020, 14, 473-479. [CrossRef]

16. Rupp, N.J.; Camenisch, U.; Seidl, K.; Rushing, E.J.; Anderegg, N.; Broglie, M.A.; Holzmann, D.; Morand, G.B. HPV-Related Multiphenotypic Sinonasal Carcinoma: Four Cases that Expand the Morpho-Molecular Spectrum and Include Occupational Data. Head Neck Pathol. 2020, 14, 623-629. [CrossRef] 
17. Rodarte, A.I.; Parikh, A.S.; Gadkaree, S.K.; Lehmann, A.E.; Faquin, W.C.; Holbrook, E.H.; Lin, D.T. Human Papillomavirus Related Multiphenotypic Sinonasal Carcinoma: Report of a Case with Early and Progressive Metastatic Disease. J. Neurol. Surg. Rep. 2019, 80, e41-e43. [CrossRef]

18. Liao, C.C.; Yu, H.J.; Lu, T.C.; Chen, Y.L.; Chen, J.W. Endoscopic View of HPV-Related Multiphenotypic Sinonasal Carcinoma. Ear Nose Throat J. 2020, 99, 96-98. [CrossRef]

19. Ward, M.L.; Kernig, M.; Willson, T.J. HPV-Related Multiphenotypic Sinonasal Carcinoma: A Case Report and Literature Review. Laryngoscope 2021, 131, 106-110. [CrossRef]

20. Hodgson, C.K.; Bayon, R.; Jensen, C.S.; Robinson, R.A.; Rajan, K.D.A. Human Papillomavirus (HPV)-Related Carcinoma of the Oropharynx with Squamous Cell and Adenoid Cystic Carcinoma-Like Features: Report of a Case. Head Neck Pathol. 2020, 15, 1007-1016. [CrossRef]

21. Oramas, D.M.; Bell, D.; Middleton, L.P. Sinonasal analogue HPV related breast multiphenotypic carcinoma, a report of a case with the first description in the breast. Diagn. Pathol. 2020, 15, 137. [CrossRef]

22. de Villiers, E.M.; Fauquet, C.; Broker, T.R.; Bernard, H.U.; zur Hausen, H. Classification of papillomaviruses. Virology 2004, 324, 17-27. [CrossRef]

23. Wenig, B.M. Recently described sinonasal tract lesions/neoplasms: Considerations for the new world health organization book. Head Neck Pathol. 2014, 8, 33-41. [CrossRef]

24. Kusafuka, K.; Yagi, H.; Baba, S.; Inagaki, H.; Tsuchiya, C.; Hirata, K.; Muramatsu, A.; Suzuki, M.; Arai, K.; Terada, T. Basaloid squamous cell carcinoma with adenoid cystic-like features of the head and neck region: A report of two cases. Pathol. Int. 2020, 70, 767-774. [CrossRef]

25. Ishida, M.; Okabe, H. Basaloid squamous cell carcinoma of the maxillary sinus: Report of two cases in association with cathepsin K expression. Oncol. Lett. 2013, 5, 1755-1759. [CrossRef]

26. El-Naggar, A.K.; Chan, J.K.C.; Grandis, J.R.; Takata, T.; Slootweg, P.J. (Eds.) WHO Classification of Head and Neck Tumours, 4th ed.; IARC: Lyon, France, 2017. 